\title{
Enrichment of Larval Fish Feed with Free Amino Acids and Proteins by Coating with Lactobacillus paracasei subsp. paracasei BGHN14 Homogenate
}

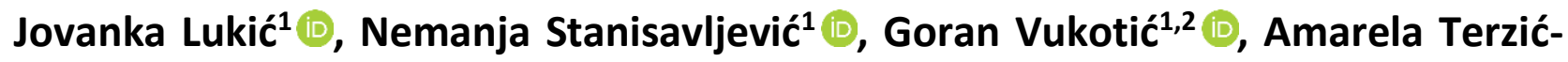

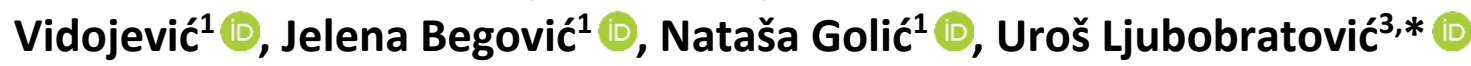

\footnotetext{
${ }^{1}$ University of Belgrade, Institute of Molecular Genetics and Genetic Engineering (IMGGE), Vojvode Stepe 444a, Belgrade, Serbia

${ }^{2}$ University of Belgrade, Faculty of Biology, Studentski trg 16, Belgrade, Serbia.

${ }^{3}$ Hungarian University of Agriculture and Life Sciences (MATE), Research Center of Fisheries and Aquaculture (HAKI), Anna-liget 35., H-5540 Szarvas, Hungary
}

\section{How to cite}

Lukić, J., Stanisavljević, N., Vukotić, G., Terzić-Vidojević, A., Begović, J., Golić, N., Ljubobratović, U. (2021). Enrichment of Larval Fish Feed with Free Amino Acids and Proteins by Coating with Lactobacillus paracasei subsp. paracasei BGHN14 Homogenate. Turkish Journal of Fisheries and Aquatic Sciences, 21, 569-573. http://doi.org/10.4194/1303-2712-v21_11_05

\section{Article History}

Received 17 April 2021

Accepted 21 June 2021

First Online 02 July 2021

\section{Corresponding Author}

Tel.: +0036704403133

E-mail: Ljubobratovic.Uros@uni-mate.hu

\section{Keywords}

Microdiet

Bacteria

Taste Stimulation

Glycine

Alanine

\begin{abstract}
This research aimed to test whether coating with Lactobacillus paracasei subsp. paracasei BGHN14 homogenate may increase soluble protein and amino acid amount on larval fish feed surface. Total amino acid and protein, as well as taste stimulating and growth promoting amino acid amounts were analyzed in coated feed samples. Results indicated that coating with BGHN14 homogenate increased the amount of soluble proteins and free Glycine on feed surface, as well as the availability of protein-bound (hydroxy-)Proline. This lab-scale research provides the basis for use of lactobacilli as resource efficient source of soluble nutrients for animal feedstuffs.
\end{abstract}

\section{Introduction}

Administration of inert feed to fish larvae substantially reduces the costs of fish farming (D'Abramo, 2002). However, inert feed does not have nutritive value comparable to live food. At first place, it does not contain satisfactory amount of water soluble nutrients (Tonheim et al., 2007). Although the reduction of soluble molecule level improves water stability of aqua-feeds, it is associated not only with lower appealing of feed to larval fish, but also to lower nutrient assimilation by larval fish, given the poor development of their digestive tract (Tonheim et al., 2007). Taste stimulation and palatability are ascribed to small watersoluble molecules including peptides (Dong, et al., 2016) and nonpolar L-amino acids, mainly Glycine (Gly), Alanine (Aln) and Proline (Pro) (Morais, 2017). Gly and Pro have also been considered as functional amino acids for fish. These amino acids are traditionally classified as non-essential, but their endogenous synthesis in rapidly growing animals is not satisfactory. They are mainly deposited in collagen proteins in growing skeleton ( $\mathrm{Li}$ and $\mathrm{Wu}, 2018$ ). Though animal and plant protein hydrolysates may serve as a good source of soluble proteins and free amino acids, their incorporation in solid feed is highly challenging due to high leaching rate (Kolkovski, 2013). Use of bacteria as protein source has gained significant attention recently. It may increase the efficiency of resource use, thus supporting the green growth initiative put forward by most countries 
worldwide (Matassa et al., 2016). Aside from providing proteins, bacterial cells can be manipulated to accumulate free amino acids using osmotic stress as a stimulant. Among others, Aln and Pro were reported as the most common compatible solutes in bacterial cells (Empadinhas and da Costa, 2008).

The aim of this paper was to evaluate whether coating of larval fish feed with Lactobacillus paracasei subsp. paracasei BGHN14 exposed to osmotic stress may increase soluble protein and free amino acid amount, including Aln, (hydroxy-)Pro and Gly, in the surface layer of OTOHIME B1 fry feed. In line with our expectations, the results obtained in this research suggest that BGHN14 strain may improve soluble nutrient levels in larval fish feed, thus supporting the use of bacteria as eco-friendly animal feed fortifiers.

\section{Materials and Methods}

Strain L. paracasei subsp. paracasei BGHN14, which was shown to be safe for larval fish (Ljubobratovic et al., 2017, 2020) was used for the preparation of feed coating mixture. BGHN14 belongs to bacterial collection of the Laboratory for Molecular Microbiology (LMM), IMGGE and has been deposited in Belgian co-ordinated collections of micro-organisms (BCCMTM). Cultivation of BGHN14 was performed as described in Lukic et al., 2019. Coating mixture was prepared by exposing BGHN14 culture in logarithmic growth phase to salinity stress (1 M NaCl) (Waśko et al., 2013) until reaching stationary growth phase (16 h). Afterwards, cells were collected, washed in $1 \mathrm{M} \mathrm{NaCl}$ solution and pulverized in liquid nitrogen in order to release intracellular molecules. Total bacterial amount in lysed BGHN14 mixture was determined via dilution method (Lukic et al., 2019). Soluble protein and amino acid levels in homogenate were determined by Bradford reagent and Trinitrobenzenesulfonate (TNBS) (Pittner, 2002), respectively. For amino acid analysis, proteins were precipitated in $1 \%$ trichloroacetic acid (TCA) at $+4^{\circ} \mathrm{C}$ for $10 \mathrm{~min}$ (low concentration of TCA was used in order to prevent the interference with TNBS assay); the efficiency of precipitation was estimated in a preliminary test by evaluating residual protein amount in precipitated samples via Bradford assay. After centrifugation at 14500 relative centrifugal force (RCF), supernatants were mixed with $0.1 \mathrm{M}$ carbonate buffer $\mathrm{pH} 8.5$ and $0.005 \%$ TNBS. Reaction (30 min of incubation at $37^{\circ} \mathrm{C}$ ) was stopped by addition of $0.25 \mathrm{M} \mathrm{HCl}$ and absorbance was read at $420 \mathrm{~nm}$. DL-Aln was used for calibration curve preparation. L-Aln and Gly amounts were assayed using commercially available kits (Cell Biolabs, Inc., San Diego, CA, US) and (hydroxy-)Proline (Pro) levels were estimated using ninhydrin assay (Carillo and Gibon, 2011; Friedman, 2004). Briefly, 100 $\mu$ l of prepared reagent ( $1 \%$ ninhydrin in $60 \%$ acetic acid and $20 \%$ ethanol.), $70 \mu \mathrm{l}$ of $96 \%$ ethanol and $30 \mu \mathrm{l}$ of sample precipitated in $1 \%$ TCA were mixed, heated at $95^{\circ} \mathrm{C}$ for $20 \mathrm{~min}$, cooled and absorbance was measured at $510 \mathrm{~nm}$. BGHN14 mixture (prepared as above) was diluted with $1.7 \times$ volume of saline (per wet weight) and stored at $-80^{\circ} \mathrm{C}$ before use. OTOHIME B1 larval feed (250-360 $\mu \mathrm{m}$ pellets, Marubeni Nishin Feed Co., Ltd., Tokyo, Japan) was coated with prepared BGHN14 extract using solid state treatment procedure. Feed was stored up to three months at $-20^{\circ} \mathrm{C}$ before experiment. Feed coating was performed on a small scale $(50 \mathrm{mg}$ of feed) using $260 \%$ moisture percentage and $200 \mathrm{mg} / \mathrm{g}$ of wet bacterial mass (and was immediately placed in oven at $50-55^{\circ} \mathrm{C}$ for drying for $4 \mathrm{~h}$ ) (Lukic et al., 2019). Total bacterial and BGHN14 growth was estimated on universal Luria Agar (LA) and MRS medium, respectively, via dilution method. Soluble protein and lipid content of the surface portion of feed granules were performed after fat extraction (Lukic et al., 2019), while amino acid amounts were estimated in non-defatted feed samples, in order to prevent the loss of L-Aln, Gly and (hydroxy-) Pro into the organic solvent phase (Reddy, 2019). Feed was tested before and after simulated leaching test. Leaching was performed by mixing of feed granules with water $(20 \mathrm{mg}$ of $\mathrm{feed} / \mathrm{ml}$ ) and rotation, using tube revolver at RT for $15 \mathrm{~min}$, which is maximal estimated time for fish to consume the feed (Pattillo, 2014). Simulation of feed sample digestion in fish larval gut was tested as described previously (Minekus et al., 2014), with modifications. Feed samples before and after water washing were resuspended in $0.1 \mathrm{M} \mathrm{Na-phosphate}$ buffer, $\mathrm{pH} 8$ (10 $\mathrm{mg}$ of feed $/ \mathrm{ml}$ ) and trypsin from bovine pancreas was added at a concentration of 100 TAME units per $\mathrm{ml}$. Samples were incubated at $37^{\circ} \mathrm{C}$ for $2 \mathrm{~h}$ with shaking. Afterwards, samples were centrifuged and amino acid amount in the supernatant was analyzed as described above. All experimental analyses were performed in triplicates. Differences between treatments were estimated using t-test or Analysis of Variances (ANOVA) with Tukey post-hoc test. In the case of the violation of variance homogeneity (estimated by Levene test), Welch's t or Welch's F-test (with GamesHowell post-hoc test) were utilized. Mean and standard deviations were calculated using SPSS 20.0 for Windows (IBM Corporation, Armonk, NY, US).

\section{Results}

Exposure of BGHN14 culture to $1 \mathrm{M} \mathrm{NaCl}$ was associated with an increase of free amino acid $(15.63 \pm 1.48$ vs. $5.04 \pm 3.06$ in control, $\mu \mathrm{g} / \mathrm{mg}$ of wet weight), (hydroxy-)Pro $(0.00253 \pm 0.00043$ vs. $0.00035 \pm 0.00003$ in control) and Gly $(4.34 \pm 0.21$ vs. $1.11 \pm 0.52$ in control) amounts in BGHN14 extract. Soluble protein amount was increased in feed samples coated with BGHN14 extract after 15 min of washing $(0.62 \pm 0.2 \mu \mathrm{g} / \mathrm{mg}$ of dried feed) in comparison to wet $(0.09 \pm 0.16)$ and dry control feed samples $(0.07 \pm 0.1)$. Gly was increased in BGHN14 coated feed samples both before $(6.27 \pm 0.33$ vs. $4.75 \pm 0.74$ in wet vs. $4.25 \pm 0.31$ in dry control feed) and after washing (1.82 \pm 0.42 vs. $0.86 \pm 0.26$ in wet vs. $0.87 \pm 0.09$ in dry control feed). On 
the other hand, L-Aln levels were reduced but only before washing $(0.29 \pm 0.11$ vs. $2.41 \pm 0.65$ in wet vs. $2.38 \pm 0.56$ in dry control feed). Survival of BGHN14 in coated feed was $7 \pm 2.6 \times 10^{4}$ bacterial cells per $\mathrm{mg}$ of dried feed sample. Total bacterial growth in coated feed $\left(9.33 \pm 3.21 \times 10^{5}\right)$ was not significantly different from (wet $\left(18.33 \pm 3,51 \times 10^{5}\right)$ and dry control $\left(12 \pm 5.57 \times 10^{5}\right)$.

Trypsin in vitro digestion of feed samples resulted in an increase of free amino acid amount in BGHN14 mixture coated feed samples $(99.94 \pm 7.14$ before and $68.03 \pm 8.38$ after leaching) in comparison to wet (72.60 \pm 5.42 before and $42.19 \pm 3.34$ after leaching) and dry control feed samples $(65.89 \pm 8.82$ before and $52.54 \pm 5.48$ after leaching). (Hydroxy-)Pro levels were increased in coated feed both before $0.00454 \pm 0.00036$ vs. $0.00377 \pm 0.0002$ in wet vs. $0.00378 \pm 0.00029$ in dry control feed) and after washing $(0.00132 \pm 0.00013$ vs. $0.00055 \pm 0.00004$ in wet vs. $0.00056 \pm 0.00026$ in dry control feed). L-Aln levels were decreased in coated feed before leaching $(0.71 \pm 0.14$ vs. $3.81 \pm 0.26$ in wet vs. $3.7 \pm 0.21$ in dry control feed).

\section{Discussion}

Successful and safe use of lactobacilli in aquaculture so far, primarily related to pathogen control, makes lactobacilli excellent candidates for enrichment of fish feed with soluble nutrients (Hoseinifar et al., 2018). Exposure of L. paracasei subsp. paracasei BGHN14 to osmotic stress in this research increased intracellular Gly and (hydroxy-)Pro concentrations. Similarly, Glaasker et. al., 1996, reported an increase of Gly and Pro in osmotically shocked L. plantarum cells. Coating of larval fish feed pellets with osmotically stressed BGHN14 cells resulted in enrichment of the surface layer of feed granules with Gly. Gly in its free form can increase the taste attractiveness of larval feed, which may alleviate the process of early weaning in larval fish, given the high content of Gly in live food (Gallagher and Brown, 1975). The efficiency of enrichment of feed granules with target molecules may be compromised either by leaching of soluble molecules during the process of feed drying (Lukic et al., 2019) or by incorporation of amino acids into the bacterial proteins during bacterial growth. The latter requires the presence of live bacteria in the coating mix, so total inactivation of bacteria (e.g. by heating) in BGHN14 extract may potentially increase the efficiency of enrichment.

Increase of Gly in BGHN14 coated feed samples was also noticeable after 15 min of exposure of coated feed granules to water, which served as a simulation of nutrient diffusion into the fish rearing water before feed ingestion by fish. Retention of soluble nutrients on the surface of feed granules is of special relevance for larval fish because of their poor stomach development and high dependence on soluble molecules present in food (Tonheim et al., 2007). In line with this, coating with BGHN14 extract reduced diffusion rate of soluble proteins, which also possess taste stimulatory effect (Dong et al., 2016). This can be explained by the findings of Zhdanov and Kasemo (2010), who showed that proteins bind to lipid bilayers via electrostatic interactions. Similar situation was seen with feed samples treated with live BGHN14 (Lukić et al., 2021); however, in this case, the retention of proteins after washing was lower, although the number of live bacteria was higher in comparison to homogenate. This suggests that lysis of bacteria may be the most important factor for the retention of soluble proteins on feed surface after washing.

Soluble proteins retained on the surface of BGHN14 extract coated feed granules may act as a potential source of valuable amino acids important for larval growth. In line with this, simulated trypsin digestion of feed samples coated with BGHN14 extract released a substantial amount of amino acids. Since this release was observed both before and after exposure of feed granules to leaching, increased digestibility of proteins was probably not dependent only on their solubility. Trypsin activation by lipid bilayer has been reported by Mahmmoud, 2005. Furthermore, protein denaturation may occur during interaction with lipid bilayers, thus increasing their digestibility (Opstvedt et al., 2003; Zhdanov and Kasemo, 2010). (Hydroxy-)Pro levels were significantly increased after simulated trypsin digestion, indicating high content of protein bound (hydroxy-)Pro in larval feed. Levels of (hydroxy)Pro were significantly increased after coating of feed samples with BGHN14 extracts both before and after washing, probably as the results of increased protein digestibility and/or solubility. Gly amounts in BGHN14 homogenate coated feed showed a statistical trend $(P=$ 0.059 before and 0.066 after washing) towards increase in comparison to dry feed samples. In contrast to (hydroxy-)Pro, this Gly is probably coming from the homogenate itself, since, according to the results of Gly measurement in trypsin digested control feed samples, it seems that Gly in larval feed is predominantly present in the free form. Alternatively, proteins containing the Gly may be resistant to trypsin digestion.

An interesting observation is the reduction of L-Aln levels in BGHN14 coated feed samples not exposed to water diffusion test. Aln has an essential role in bacterial wall build-up (Wei et al., 2016). Its leakage from the surface of feed granules may lead to excess growth of pathogenic bacteria and biofilm formation on surfaces of fish rearing systems. It could be assumed that Aln was incorporated into the cell walls of BGHN14 during coating/drying procedure. Peptidoglycan synthesis has been reported by non-viable bacterial extracts (Egan et al., 2015), as well as in vitro L- to D-Aln conversion (Pierce et al., 2008). Comparison with feed samples treated with live bacteria (Lukić et al., 2021) revealed no association of Aln reduction level with viable bacteria count present in feed samples. However, the role of live or lysed bacteria in Aln depletion from feed samples remains to be investigated. 
We note here that lysis with liquid nitrogen failed to completely inactivate BGHN14 cells (survival of BGHN14 in coated feed was $7 \pm 2.6 \times 10^{4}$ bacterial cells per $\mathrm{mg}$ of dried feed sample). As elaborated by Geciova et al., 2002, mechanical methods of cell disruption, though being quite efficient for the release of intracellular soluble molecules, do not completely kill bacteria in the sample. This can lead to non-uniformity of results due to variations in the viability of residual bacteria during sample storage. Therefore, it is necessary to perform detailed examination to determine the effect of feed coating with BGHN14 mixture after different storage periods.

\section{Conclusion}

To summarize, this research demonstrated that application of lactobacilli homogenate increases the amount of free Gly and the availability of protein bound Gly and (hydroxy-)Pro in larval fish feed. It further contributes to retention of soluble proteins in larval feed after water exposure, suggesting the potential for use of lactobacilli extracts as encapsulation agents for the prevention of soluble nutrient leaching. This may promote feed acceptance and skeleton development in larval fish.

\section{Ethical Statement}

This work did not include experiments in animals. All authors meet the standards of ethical responsibility listed by the publisher.

\section{Funding Information}

This research has received funding from the European Union's Horizon 2020 research and innovation programme under grant agreement No. 652831 (AQUAEXCEL ${ }^{2020}$ ), European Regional Development Fund and the Hungarian Government within the project GINOP-2.3.2-15-2016-00025 and the National Project No. 173019 of the Ministry of Education, Science and Technological Development of the Republic of Serbia. This output reflects only the author's view and the funders cannot be held responsible for any use that may be made of the information contained therein. The funders were not involved in study design, data analysis and preparation of the manuscript.

\section{Author Contribution}

$J L$ was involved in study conception and design, acquisition, analysis and interpretation of the data, as well as the preparation of manuscript draft. NS and GV were involved in data acquisition and critical revision of the manuscript. ATV, JB and NG were involved in the conception of the study and critical revision of the manuscript. UL was involved in study conception and design, interpretation of the data and preparation of manuscript draft. All authors approved the final version of the manuscript and agreed to be accountable for all aspects of the work, including accuracy and integrity of presented data.

\section{Conflict of Interest}

The authors declare that they have no known competing financial interests or personal relationships that could have appeared to influence the work reported in this paper.

\section{Acknowledgements}

The authors thank to Nikola Vojvodić, IMGGE, for technical assistance during work.

\section{References}

Bryan, D.D.S.L., \& Classen, H.L. (2020). In vitro methods of assessing protein quality for poultry. Animals, 10, 551. https://doi.org/10.3390/ani10040551

Carillo P, Gibon Y (2011) PROTOCOL: Extraction and determination of proline. Retrieved from https://fdocuments.in/document/protocol-extractionand-determination-of-proline.html

D'Abramo, L.R. (2002). Challenges in developing successful formulated feed for culture of larval fish and crustaceans. In L.E. Cruz-Suárez, D. Ricque-Marie, M. Tapia-Salazar, M.G. Gaxiola-Cortés, N. Simoes (Eds.), Avances en Nutrición Acuícola VI. Memorias del VI Simposium Internacional de Nutrición Acuícola (pp. 143151). Cancún, Quintana Roo, México.

Dong, C., He, G., Mai, K., Zhou, H., Xu, W. (2016). Palatability of water-soluble extracts of protein sources and replacement of fishmeal by a selected mixture of protein sources for juvenile turbot (Scophthalmus maximus). Journal of Ocean University of China, 15, 561-567. https://doi.org/10.1007/s11802-016-2898-8

Egan, A.J., Biboy, J., van't Veer, I., Breukink, E., Vollmer, W. (2015). Activities and regulation of peptidoglycan synthases. Philosophical Transactions of the Royal Society B: Biological Sciences, 370, 20150031. https://doi.org/10.1098/rstb.2015.0031

Empadinhas, N., \& da Costa, M. (2008). Osmoadaptation mechanisms in prokaryotes: Distribution of compatible solutes. International Journal of Microbiology, 11, 151161. https://doi.org/10.2436/20.1501.01.55

Gallagher, M., \& Brown, W.D. (1975). Composition of San Francisco Bay brine shrimp (Artemia salina). Journal of Agricultural and Food Chemistry, 23, 630-632. https://doi.org/10.1021/jf60200a008

Geciova, J., Bury, D., Jelen, P. (2002). Methods for disruption of microbial cells for potential use in the dairy industry a review. International Dairy Journal, 12, 541-553. https://doi.org/10.1016/s0958-6946(02)00038-9

Glaasker, E., Konings, W.N., Poolman, B. (1996). Osmotic regulation of intracellular solute pools in Lactobacillus plantarum. Journal of Bacteriology, 178, 575-582. https://doi.org/10.1128/jb.178.3.575-582.1996

Hoseinifar, S.H., Sun, Y.Z., Wang, A., Zhou, Z. (2018). Probiotics as means of diseases control in aquaculture, a review of 
current knowledge and future perspectives. Frontiers in Microbiology, 9, 2429.

https://doi.org/10.3389/fmicb.2018.02429

Kolkovski, S. (2013). Microdiets as alternatives to live feeds for fish larvae in aquaculture: Improving the efficiency of feed particle utilization. Advances in Aquaculture Hatchery Technology (pp. 203-222). https://doi.org/10.1533/9780857097460.1.203

Li, P., \& Wu, G. (2018). Roles of dietary glycine, proline, and hydroxyproline in collagen synthesis and animal growth. Amino Acids, 50, 29-38. https://doi.org/10.1007/s00726-017-2490-6

Ljubobratovic, U., Kosanovic, D., Demény, F., Krajcsovics, A., Vukotic, G., Stanisavljevic, N., Golic, N., Jeney, G., Lukic, J. (2020). The effect of live and inert feed treatment with lactobacilli on weaning success in intensively reared pike-perch larvae. Aquaculture, 516, 734608. https://doi.org/10.1016/j.aquaculture.2019.734608

Ljubobratovic, U., Kosanovic, D., Vukotic, G., Molnar, Z., Stanisavljevic, N., Ristovic, T., Peter, G., Lukic, J., Jeney, G. (2017). Supplementation of lactobacilli improves growth, regulates microbiota composition and suppresses skeletal anomalies in juvenile pike-perch (Sander lucioperca) reared in recirculating aquaculture system (RAS): a pilot study. Research in Veterinary Sciences, 115, 451-462. ttps://doi.org/10.1016/j.rvsc.2017.07.018

Lukić, J., Stanisavljević, N., Vukotić, G., Terzić-Vidojević, A., Begović, J., Golić,. N., Ljubobratović,. U. (2021). Supporting data to „Enrichment of larval fish feed with free amino acids and proteins by coating with Lactobacillus paracasei subsp. paracasei BGHN14 homogenate". ResearchGate

Lukic, J., Vukotic, G., Stanisavljevic, N., Kosanovic, D., Molnar, Z., Begovic, J., Terzic-Vidojevic, A., Jenney, G., Ljubobratovic, U. (2019). Solid state treatment with Lactobacillus paracasei subsp. paracasei BGHN14 and Lactobacillus rhamnosus BGT10 improves nutrient bioavailability in granular fish feed. PLOS ONE, 14, e0219558.

https://doi.org/10.1371/journal.pone.0219558

Mahmmoud, Y.A. (2005). Stabilization of trypsin by association to plasma membranes: implications for tryptic cleavage of membrane-bound $\mathrm{Na}$, K-ATPase. Biochimica et Biophysica Acta, 1720, 110-116. https://doi.org/10.1016/j.bbamem.2005.11.001

Matassa, S., Boon, N., Pikaar, I., Verstraete, W. (2016). Microbial protein: future sustainable food supply route with low environmental footprint. Microbial Biotechnology, 9, 568-575.

https://doi.org/10.1111/1751-7915.12369
Minekus $M$, Alminger M, Alvito $P$, Ballance $S$, Bohn T, Bourlieu $C$, Carrière $F$, Boutrou $R$, Corredig $M$, Dupont $D$ et al. (2014) A standardised static in vitro digestion method suitable for food - an international consensus. Food \& Function 5:1113-1124. doi:10.1039/c3fo60702j

Morais, S. (2017). The physiology of taste in fish: potential implications for feeding stimulation and gut chemical sensing. Reviews in Fisheries Science and Aquaculture, 25, 133-149.

https://doi.org/10.1080/23308249.2016.1249279

Opstvedt, J., Nygard, E., Samuelsen, T.A., Venturini, G., Luzzana, U., Mundheim, H. (2003). Effect on protein digestibility of different processing conditions in the production of fish meal and fish feed. Journal of the Science of Food and Agriculture, 83, 775-782. https://doi.org/10.1002/jsfa.1396

Pattillo DA (2014) Standard operating procedures - feeding practices for recirculating aquaculture. Extension and Outreach Publications. 233. Retrieved from http://lib.dr.iastate.edu/extension_pubs/233

Pierce, K.J., Salifu, S.P., Tangney, M. (2008). Gene cloning and characterization of a second alanine racemase from Bacillus subtilis encoded by yncD. FEMS Microbiology Letters, 283, 69-74. https://doi.org/10.1111/j.15746968.2008.01151.x

Pittner F (2002) Immobilized biomolecules in bioanalysis. In: Schalkhammer TGM (ed) Analytical Biotechnology. Springer Basel AG, Basel, Switzerland. p. 38. doi:10.1007/978-3-0348-8101-2

Reddy, M.K. (2019). Amino acid. Encyclopædia Britannica, inc. Retrieved from https://www.britannica.com/science/amino-acid

Tonheim, S.K., Nordgreen, A., Høgøy, K., Hamre, K., Rønnestad, I. (2007). In vitro digestibility of water-soluble and waterinsoluble protein fractions of some common fish larval feeds and feed ingredients. Aquaculture, 262, 426-435. https://doi.org/10.1016/j.aquaculture.2006.10.030

Waśko A, Polak-Berecka M, Gustaw W (2013) Increased viability of probiotic Lactobacillus rhamnosus after osmotic stress. Acta Alimentaria 42:520-528. doi:10.1556/AAlim.42.2013.4.7

Wei, Y., Qiu, W., Zhou, X.D., Zheng, X., Zhang, K.K., Wang, S.D., Li, Y.Q., Cheng, L., Li, J.Y., Xu, X. et al. (2016). Alanine racemase is essential for the growth and interspecies competitiveness of Streptococcus mutans. International Journal of Oral Science, 8, 231-238. https://doi.org/10.1038/ijos.2016.34

Zhdanov, V.P., \& Kasemo, B. (2010). Protein adsorption and desorption on lipid bilayers. Biophysical Chemistry, 146, 60-64. https://doi.org/10.1016/j.bpc.2009.10.005 